\title{
Deposition and Tribological Properties of Sulfur-Doped DLC Films Deposited by PBII Method
}

\author{
Nutthanun Moolsradoo and Shuichi Watanabe \\ Nippon Institute of Technology, 4-1 Gakuendai, Miyashiro Machi, Saitama 345-8501, Japan \\ Correspondence should be addressed to Nutthanun Moolsradoo, nutthanun.moo@kmutt.ac.th \\ Received 26 March 2010; Accepted 12 October 2010 \\ Academic Editor: Manish U. Chhowalla
}

Copyright ( $) 2010$ N. Moolsradoo and S. Watanabe. This is an open access article distributed under the Creative Commons Attribution License, which permits unrestricted use, distribution, and reproduction in any medium, provided the original work is properly cited.

\begin{abstract}
Sulfur-doped diamond-like carbon films (S-DLC) fabricated from $\mathrm{C}_{2} \mathrm{H}_{2}$ and $\mathrm{SF}_{6}$ mixtures were used to study the effects of sulfur content and negative pulse bias voltage on the deposition and tribological properties of films prepared by plasma-based ion implantation (PBII). The structure and relative concentration of the films were analyzed by Raman spectroscopy and Auger electron spectroscopy. Hardness and elastic modulus of films were measured by nanoindentation hardness testing. Tribological characteristics of films were performed using a ball-on-disk friction tester. The results indicate that with the increasing sulfur content, the hardness and elastic modulus decrease. Additionally, by changing the negative pulse bias voltage from $0 \mathrm{kV}$ to $-5 \mathrm{kV}$, the hardness and elastic modulus increase, while the friction coefficient and specific wear rate tends to decrease. Moreover, at a negative pulse bias voltage of $-5 \mathrm{kV}$ and flow-rate ratio of $1: 2$, there is considerable improvement in friction coefficient of 0.05 under ambient air is due to the formation of a transfer films on the interface. The decrease in the friction coefficient of films doped with 4.9 at.\% sulfur is greater under high vacuum (0.03) than under ambient air $(>0.1)$.
\end{abstract}

\section{Introduction}

Diamond-like carbon (DLC) coatings are metastable amorphous films that exhibit unique combinations of properties such as high hardness and elastic modulus, low friction coefficients, optical transparency, good wear resistance, and excellent corrosion resistance. Thus, these films are commonly applied as wear-resistant protective coatings in the magnetic storage, automobile, tooling, and biomedical industries [1-3]. Several techniques for creating DLC films include: magnetron sputtering deposition (MSD), ion beamassisted deposition (IBAD), plasma-assisted chemical vapor deposition (PACVD) or plasma-enhanced chemical vapor deposition (PECVD), plasma-based ion implantation (PBII), and others [4-7]. However, DLC films have no sufficient friction endurance and friction coefficient depending on their application environment. In order to tackle these problems, the films could be modified by incorporation of elements, such as fluorine, silicon, and various elements.

Plasma-based ion implantation (PBII), also known as plasma immersion ion implantation (PIII), was initially developed by Conrad and Castagna [8] in 1986. PBII has been developed to improve the properties of DLC films [9]. In this technique, samples are immersed in plasma and biased to a negative potential. A plasma sheath then forms and accelerated ions bombard the exposed surface of the samples. This is a relatively new technique that has been shown to be an effective for surface modification [10]. Additionally, PBII is uniquely advantageous. Notable advantages include: low working temperature less than $100^{\circ} \mathrm{C}$, which avoids the film quality degradation such as loose and rough surface structure, and the DLC graphitization caused by normal chemical vapor deposition and plasma laser deposition, which are performed at higher working temperatures [11] and high ion energy (implanting voltage), which is helpful to transfer $\mathrm{sp}^{2}$ bond to $\mathrm{sp}^{3}$ bond ones, as a result of DLC films rich in $\mathrm{sp}^{3}$ bond and thus of high hardness and good tribological properties [12].

Previous studies have shown that the tribological properties of the DLC films are strongly dependent on the nature of the films and deposition methods and conditions, and they are very sensitive to the testing environment [13-15]. 


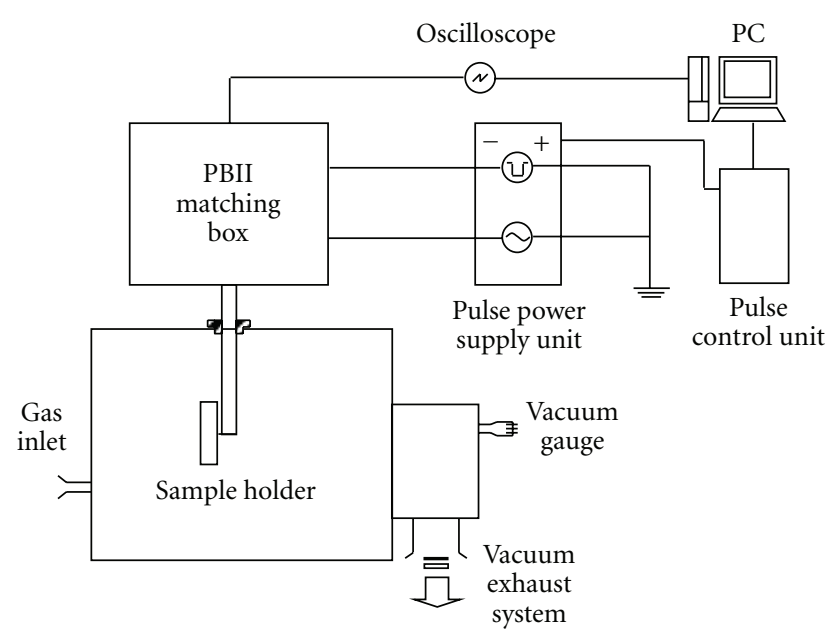

FIGURE 1: Schematicrepresentation of the PBII apparatus used in this experiment.

In earlier studies byFreyman et al. [16], it was shown that the hydrogenate carbon films doped with 5\% sulfur have low friction coefficient $(<0.01)$ under ambient air with relative humidity. Together with the results ofTagawa et al. [17], it was shown the hydrogenated carbon films have low friction coefficient in humid air. Friction coefficient and friction endurance of films were more excellent under high vacuum than under ambient air [18]. Moreover, bond strengths in diatomic molecules indicate that C-S bonds is high, which should result in an ultra-low friction coefficient [19].

In this paper, Plasma-based ion implantation (PBII) was utilized to prepare sulfur-doped DLC films (henceforth denoted as S-DLC films) using acetylene $\left(\mathrm{C}_{2} \mathrm{H}_{2}\right)$ and sulfur hexafluoride $\left(\mathrm{SF}_{6}\right)$ as precursors. The deposition was performed as a function of $\mathrm{C}_{2} \mathrm{H}_{2}: \mathrm{SF}_{6}$ ratio at a deposition pressure of $2 \mathrm{~Pa}$. The aim of this study was to investigate the effects of sulfur content and negative pulse bias voltages on the deposition and tribological properties under ambient air and high vacuum of the films. Film properties were investigated by Raman spectroscopy, Auger electron spectroscopy, nano-indentation hardness tester and ball-on-disk friction tester.

\section{Experimental Details}

A schematic representation of the PBII apparatus used is shown in Figure 1. The inner dimensions of the vacuum chamber are $600 \times 630 \times 200 \mathrm{~mm}^{3}$, with residual pressure of about $1 \times 10^{-4} \mathrm{~Pa}$. The plasma was generated by a radio frequency (RF, 13.6 MHz) glow discharge and a negative high voltage pulse power supply that is connected to the sample holder. This PBII apparatus can alternate between implantation and deposition. Thus, by optimizing the PBII processes and the corresponding parameters, various modified layers or coatings can be prepared.

Si (100) wafers, $0.7 \mathrm{~mm}$ thick, were used as substrates. The wafers were sputter cleaned with $\mathrm{Ar}^{+}$for $20 \mathrm{~min}$ to remove surface contaminants and surface oxides using a negative pulse bias voltage (henceforth denoted as a bias voltage) of $-10 \mathrm{kV}$. Using a bias voltage of $-20 \mathrm{kV}$, the DLC film interlayer was first deposited with $\mathrm{CH}_{4}$ for $60 \mathrm{~min}$ to improve the adhesion between the film and the substrate. The S-DLC films were deposited from gaseous mixtures of $\mathrm{C}_{2} \mathrm{H}_{2}$ and $\mathrm{SF}_{6}$ (Acetylene and sulfur hexafluoride) at three different ratios (henceforth denoted as a C/S flow-rate ratio), $1: 2,1: 1$, and $2: 1$. The bias voltage was set to different values, $0 \mathrm{kV}$ and $-5 \mathrm{kV}$, at an RF power of $300 \mathrm{~W}$. The pulse frequency was set to $1 \mathrm{kHz}$ at a pulse width of $5 \mu \mathrm{s}$ and a pulse delay of $25 \mu \mathrm{s}$, respectively. The deposition pressure was set to $2 \mathrm{~Pa}$ and total deposited thickness of the films was approximately $500 \mathrm{~nm}$. The deposition conditions for the SDLC films are listed in Table 1. For comparison, PBII was utilized in preparing the DLC films (henceforth denoted as a $\mathrm{CH}$-DLC film) using $\mathrm{C}_{2} \mathrm{H}_{2}$ as precursor gas. The deposition conditions were similar to the S-DLC films conditions mentioned earlier. Additionally, magnetron sputtering was utilized to prepare the DLC film (henceforth denoted as a DLC-SP film) on silicon (100) substrates using C (graphite) as a target, at $3 \mathrm{~Pa}$ chamber pressure. $500 \mathrm{~W}$ of RF power was applied to the $\mathrm{C}$ target and $\mathrm{Ar}^{+}$was used as sputtering gas. The film thickness for both films was also set close to $500 \mathrm{~nm}$.

The structure and relative concentration of films were analyzed using Raman spectroscopy (JASCO NRS-1000 DT, beam diameter $=4 \mathrm{um}$, and wavelength $=532 \mathrm{~nm}$ ) and Auger electron spectroscopy. The hardness and elastic modulus of films were measured by a nano-indentation hardness tester. We used a pyramid diamond tip (Berkovich-type) with an indentation load of $300 \mu \mathrm{N}$. The internal stress was determined by measuring the film curvature by means of stylus profilometry and by applying Stoney's equation, as described in detail in the literature [20]. The tribological properties of the films were measured using a ball-on-disk friction tester (CSEM; Tribotester), which can be used for measurements under ambient air and high vacuum. In the friction test, a dry sliding test was carried out using a ball indenter, AISI440C (SUS440C, diameter of $6.0 \mathrm{~mm}$ ) under a normal applied load of $3 \mathrm{~N}$, rotation radius of $4 \mathrm{~mm}$, linear speed of $31.4 \mathrm{~mm} / \mathrm{s}$, and 6000 frictional rotations. The tests were performed under ambient air and a high vacuum $\left(1.0 \sim 5.0 \times 10^{-5} \mathrm{~Pa}\right)$ at room temperature. The friction endurance of the films (film failure) was defined as the number of cycles (times) when the DLC film was just worn out, with a sharply increasing friction coefficient. In addition, the area of an abraded cross section of wear mark after friction tests was measured to calculate specific wear rate.

\section{Results}

3.1. Raman Spectra. The Raman spectra obtained are shown in Figure 2. The results show the Raman spectra of $\mathrm{CH}$ DLC films, DLC-SP film, and S-DLC films, fabricated at various $\mathrm{C} / \mathrm{S}$ flow rate ratios and bias voltages and deposited on silicon substrates. The position of $\mathrm{G}$ band is related to bond-angle disorder, or $\mathrm{sp}^{3}$ bonding content, while the $I_{\mathrm{D}} / I_{\mathrm{G}}$ ratio is proportional to the ratio of $\mathrm{sp}^{2} / \mathrm{sp}^{3}[21,22]$. These two factors play the most important role in determining 
TABle 1: Deposition conditions for S-DLC films, CH-DLC films, and DLC-SP film.

\begin{tabular}{lcccc}
\hline Sample no. & Bias voltages $(\mathrm{kV})$ & Gas flow-rate ratios $\left(\mathrm{C}_{2} \mathrm{H}_{2}: \mathrm{SF}_{6}\right)$ or $(\mathrm{C} / \mathrm{S})$ & RF power $(\mathrm{W})$ & Deposition pressure $(\mathrm{Pa})$ \\
\hline S-DLC 1 & 0 & $2: 1$ & 300 & 2 \\
S-DLC 2 & 0 & $1: 1$ & 300 & 2 \\
S-DLC 3 & 0 & $1: 2$ & 300 & 2 \\
S-DLC 4 & -5 & $2: 1$ & 300 & 2 \\
S-DLC 5 & -5 & $1: 1$ & 300 & 2 \\
S-DLC 6 & -5 & $1: 2$ & 300 & 2 \\
CH-DLC 1 & 0 & $\mathrm{C}_{2} \mathrm{H}_{2}$ & 300 & 2 \\
CH-DLC 2 & -5 & $\mathrm{C}_{2} \mathrm{H}_{2}$ & \\
DLC-SP 1 & & DLC-SP film/target; C/pressure; 3 Pa/RF power; 500 W/gas; Ar & \\
\hline
\end{tabular}

the Raman spectra. In particular, the ratio of $\mathrm{sp}^{2} / \mathrm{sp}^{3}$ is one of the most important factors governing the quality of the DLC films. Generally, the lower the ratio, the closer the properties of DLC films approach to diamond. From Figure 2, the S-DLC films fabricated in this experiment show a broad spectrum composed of a D band $\left(1.350 \mathrm{~cm}^{-1}\right)$ and a $\mathrm{G}$ band $\left(1.580 \mathrm{~cm}^{-1}\right)$, which is similar to the peaks observed in conventional DLC films. The G peak of the SDLC films shifts from $1.558 \mathrm{~cm}^{-1}(0 \mathrm{kV} / 2: 1)$ to $1.569 \mathrm{~cm}^{-1}$ $(0 \mathrm{kV} / 1: 2)$, while the $I_{\mathrm{D}} / I_{\mathrm{G}}$ intensity ratio increases from 0.77 to 0.91 with sulfur incorporation (or as the C/S flowrate ratio is decreased). For a bias voltage of $-5 \mathrm{kV}$, the G peak shifts from $1.547(2: 1)$ to $1.555(1: 2)$, while the $I_{\mathrm{D}} / I_{\mathrm{G}}$ intensity ratio increase from 0.70 to 0.82 , as sulfur is incorporation. The microstructure changes result from sulfur incorporation, since the $G$ peak position shifts towards higher, while the $I_{\mathrm{D}} / I_{\mathrm{G}}$ intensity ratio increases. These results indicate an increase of number or size of graphitic domains [23], that is, an increase of $\mathrm{sp}^{2}$ bonds ( $\mathrm{sp}^{3}$ decreases) and the formation of $\mathrm{sp}^{2}$ clusters. Additionally, microstructure changes occur with bias voltage changes from $0 \mathrm{kV}$ to $-5 \mathrm{kV}$. In fact, a greater fraction of $\mathrm{sp}^{3}$ bonds can be obtained when the ion energy is enough for displacement of lowenergy $\mathrm{sp}^{3}$ bonds. Meanwhile, when the mobility of atoms on the growing surface is enhanced by ion bombardment, the disorder of the $\mathrm{C}$ structure can be induced, resulting in $\mathrm{sp}^{3}$ bonds which increase by increasing the ion energy. Both CH-DLC films and DLC-SP film also have a broad spectrum composed of a D band and a G band, similar to the peaks observed in conventional DLC films.

3.2. Surface Hardness and Elastic Modulus. The hardness and elastic modulus from all samples are shown in Figure 3. The figure shows the results from CH-DLC films, DLC-SP film, and S-DLC films calculated from a force curve obtained by the nano-indentation hardness test. Every value of hardness and elastic modulus was measured nine times, from which an average was obtained. When the penetration depth is below $5 \%$ of the film thickness, the hardness measurement is unaffected by the substrate [24]. Meanwhile, the maximum penetration depth of films in this paper was about $10 \%$ of the total film thickness. However, the influence of the substrate on the final hardness values is expected to be negligible, since both the substrate and film hardness are within the

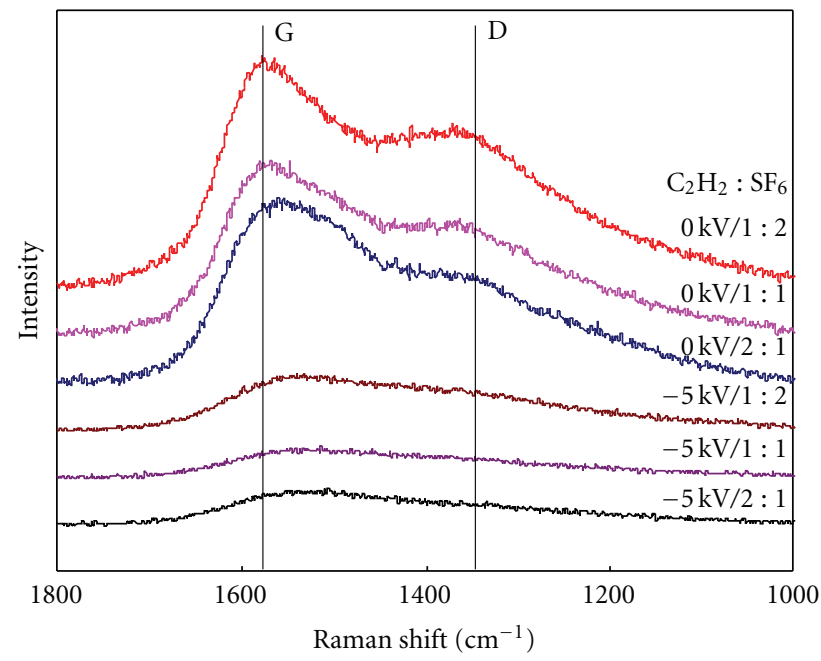

Figure 2: Raman spectra of CH-DLC films, DLC-SP film, and SDLC films.

same order of magnitude. Moreover, for the softer films, the absence of piled up material around the indentation impressions suggests that there was no important constraint imposed on the plasticity in the film by the relatively harder, more undeformable substrate.

From the Figure 3, it is clear that the hardness and elastic modulus of the S-DLC films gradually decrease with sulfur incorporation that is, the C/S flow-rate ratio decreases from $2: 1$ down to $1: 1$ and decreases drastically for a ratio of $1: 2$. Additionally, both hardness and elastic modulus also decrease as the bias voltage changes from $-5 \mathrm{kV}$ to $0 \mathrm{kV}$. It indicates that too much sulfur content doping is not in order to maintain the high hardness and elastic modulus of the undoped DLC film, which is presented in Table 2.

The hardness and elastic modulus of S-DLC films can increase values up to $14.8 \mathrm{GPa}$ and $124.3 \mathrm{GPa}$ with a bias voltage of $-5 \mathrm{kV}$ and a C/S flow rate ratio of $2: 1$ (slightly lower than that of the DLC-SP film). The increases in the film hardness and elastic modulus is believed to be partly due to the changes in the microstructure, as concluded from Raman analysis, that is, more formation of $\mathrm{sp}^{3}$ clusters with decreases in sulfur content, such as from $4.9 \%$ to $2.9 \%$ sulfur at bias voltage of $0 \mathrm{kV}$, and bias voltage changes from $0 \mathrm{kV}$ 
TABLE 2: Hardness, elastic modulus relative concentration values of all films as a function of bias voltages, C/S flow-rate ratios, and various methods.

\begin{tabular}{|c|c|c|c|c|c|c|c|}
\hline \multirow{2}{*}{ Sample no. } & \multirow{2}{*}{ Bias voltages $(\mathrm{kV})$} & \multirow{2}{*}{$\mathrm{C} / \mathrm{S}$ flow-rate ratio } & \multirow{2}{*}{ Hardness (GPa) } & \multirow{2}{*}{ Elastic modulus (GPa) } & \multicolumn{3}{|c|}{ Relative concentration (at.\%) } \\
\hline & & & & & Sulfur & Fluorine & Carbon \\
\hline S-DLC 1 & 0 & $2: 1$ & 6.7 & 55.8 & 2.9 & 1.6 & 95.5 \\
\hline S-DLC 2 & 0 & $1: 1$ & 6.0 & 50.2 & 3.3 & 2.0 & 94.7 \\
\hline S-DLC 3 & 0 & $1: 2$ & 4.8 & 36.2 & 4.9 & 2.3 & 92.8 \\
\hline S-DLC 4 & -5 & $2: 1$ & 14.8 & 124.3 & - & - & - \\
\hline S-DLC 5 & -5 & $1: 1$ & 13.0 & 115.2 & - & - & - \\
\hline S-DLC 6 & -5 & $1: 2$ & 8.9 & 83.7 & - & - & - \\
\hline CH-DLC 1 & 0 & $\mathrm{C}_{2} \mathrm{H}_{2}$ & 7.9 & 92.2 & - & - & - \\
\hline CH-DLC 2 & -5 & $\mathrm{C}_{2} \mathrm{H}_{2}$ & 9.8 & 129.6 & - & - & - \\
\hline DLC-SP & \multicolumn{2}{|c|}{ Target; C, Gas; Ar } & 15.5 & 171.7 & - & - & - \\
\hline \multicolumn{3}{|c|}{ Si (100) wafer } & 10.4 & 154.1 & 一 & - & - \\
\hline
\end{tabular}
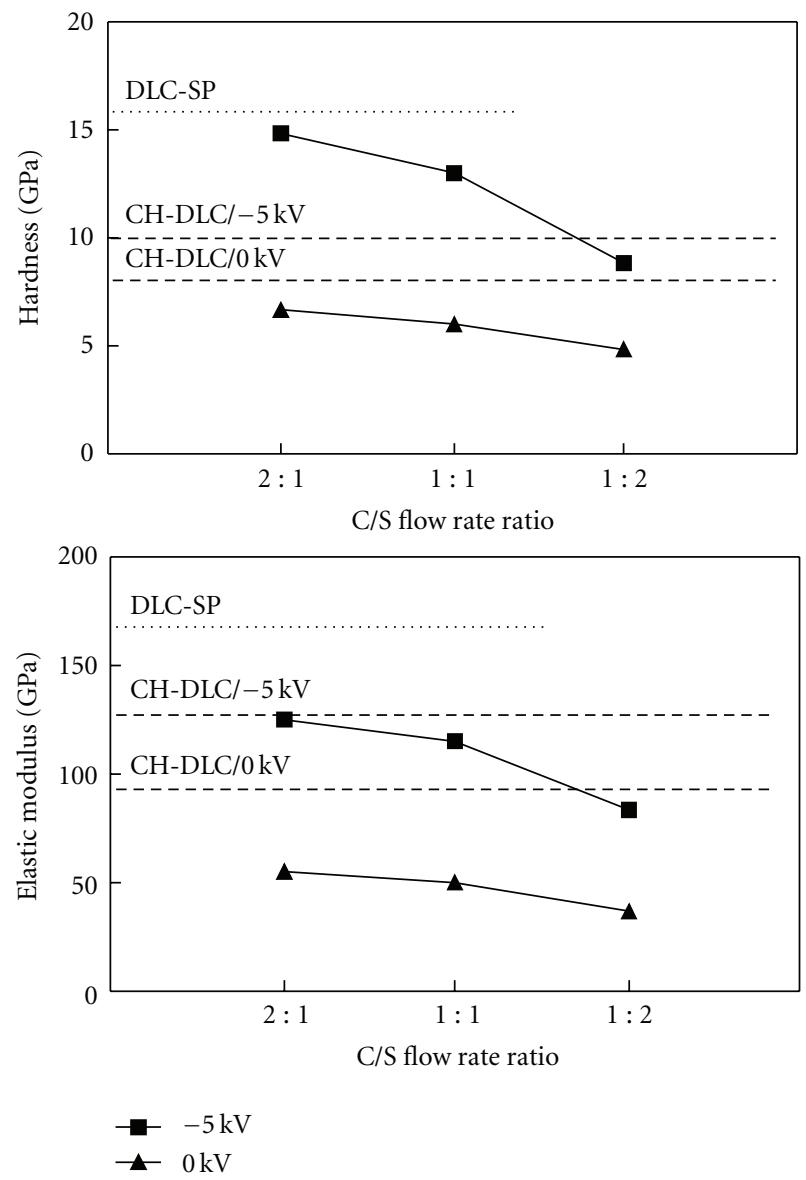

FIGURE 3: Nano indentation hardness and Elastic modulus values of CH-DLC films, DLC-SP film, and S-DLC films.

to $-5 \mathrm{kV}$. This trend shows that the films gradually lose their DLC character with increasing sulfur content in the plasma. Additionally, for the DLC-SP film, the highest hardness and elastic modulus measured are approximately 15.5 and 171.7 GPa, respectively. This is due to largest formation of $\mathrm{sp}^{3}$ clusters. CH-DLC films also show higher hardness and elastic modulus with bias voltage changes from $0 \mathrm{kV}$ to $-5 \mathrm{kV}$.
3.3. Friction Coefficient. The friction coefficients of $\mathrm{CH}$ DLC films, DLC-SP film, and S-DLC films measured under ambient air are shows in Figure 4.

The influence of the bias voltages on the friction coefficient of the S-DLC films was examined first (Figure 4). The SDLC films prepared with bias voltage of $0 \mathrm{kV}$ had an unstable friction coefficient and failed easily during tests. The films prepared at a bias voltage of $-5 \mathrm{kV}$ are stable, have a relatively lower friction coefficient and longer friction endurance. The main reasons for the early failure of the films deposited at the low bias voltage of $0 \mathrm{kV}$ were the lower hardness and elastic modulus, and higher internal stress of the films, which are presented in Tables 2 and 3. The increased friction coefficient must be caused by the increased frictional force, which is the product of the contact area and the shear strength at the ball-film interface. In fact, the decreased film hardness and elastic modulus with bias voltage of $0 \mathrm{kV}$ results in difficulty supporting the load, which can increase the contact area at the ball-film interface. Thus, with a decrease of film hardness and elastic modulus, the friction coefficient could tend to increase.

The specific wear rate of the S-DLC films is affected by the bias voltage. Since the S-DLC films prepared with bias voltage of $0 \mathrm{kV}$ fail during friction testing, the wear resistance of the S-DLC films decreases. Additionally, the wear rate of the S-DLC films deposited with bias voltage of $-5 \mathrm{kV}$ is low, in the order of $1.7 \times 10^{-7} \mathrm{~mm}^{3} / \mathrm{N} \cdot \mathrm{m}$ at a $\mathrm{C} / \mathrm{S}$ flow-rate ratio of $1: 1$, while the films with bias voltage of $0 \mathrm{kV}$ are higher, in the order of $4.36 \times 10^{-7} \mathrm{~mm}^{3} / \mathrm{N} \cdot \mathrm{m}$ at the same $\mathrm{C} / \mathrm{S}$ flowrate ratio. The wear rate decreases as the bias voltage changes from $0 \mathrm{kV}$ to $-5 \mathrm{kV}$.

The friction coefficient of the S-DLC film with the bias voltage of $-5 \mathrm{kV}$, at C/S flow-rate ratio of $1: 2$, is relatively stable and demonstrates a considerable improvement in the tribological properties, with the friction coefficient of 0.05 . It is speculated that the formation of a transfer films on the interface is always associated with friction reduction by S-DLC films, which is seen in Figure 5 micrographs of the SUS440C balls after 6000 rotations in the friction test. The transfer layer on the surface of the ball can effectively prevent direct contact between the S-DLC film and the ball and act as a lubricating layer resulting in very low friction and wear 


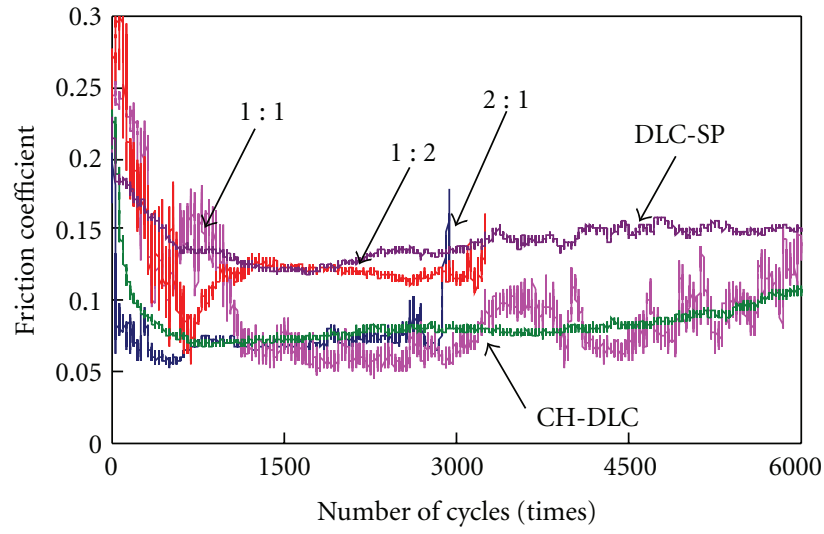

(a)

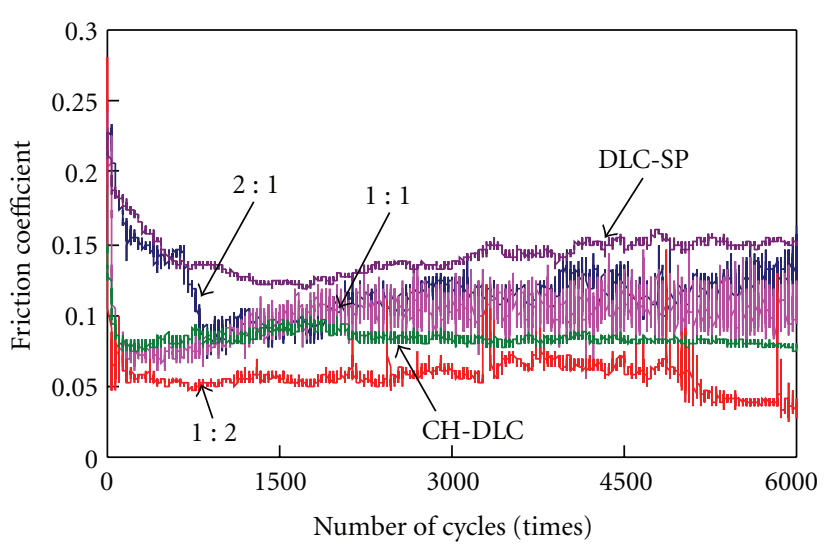

(b)

FIgURE 4: Changes in friction coefficients under ambient air with bias voltage of (a) $0 \mathrm{kV}(\mathrm{b})-5 \mathrm{kV}$.

TABLE 3: Internal stress values of S-DLC films as a function of bias voltages and $\mathrm{C} / \mathrm{S}$ flow-rate ratios.

\begin{tabular}{lccc}
\hline Sample no. & $\begin{array}{c}\text { Bias voltages } \\
(\mathrm{kV})\end{array}$ & $\begin{array}{c}\text { C/S flow-rate } \\
\text { ratios }\end{array}$ & $\begin{array}{c}\text { Internal stress } \\
(\mathrm{GPa})\end{array}$ \\
\hline S-DLC 1 & 0 & $2: 1$ & 1.10 \\
S-DLC 2 & 0 & $1: 1$ & 1.03 \\
S-DLC 3 & 0 & $1: 2$ & 1.05 \\
S-DLC 4 & -5 & $2: 1$ & 0.93 \\
S-DLC 5 & -5 & $1: 1$ & 0.79 \\
S-DLC 6 & -5 & $1: 2$ & 0.40 \\
\hline
\end{tabular}

on both film and the ball. However, although the hardness and elastic modulus is low, the high sulfur incorporation number at $\mathrm{C} / \mathrm{S}$ flow-rate ratio of $1: 2$ and transfer films were subject to give a lowest friction coefficient. This indicates that the friction coefficient of this film is affected by the sulfur incorporation more than the hardness and elastic modulus of films.

Figure 6 shows the friction coefficient of the S-DLC films fabricated at a bias voltage of $0 \mathrm{kV}$ under high vacuum at room temperature. This figure shows that the friction coefficients of S-DLC films have stable and low values, less than half of values measured under ambient air. In particular, the friction coefficient value at a $\mathrm{C} / \mathrm{S}$ flow rate ratio of $1: 2$ under high vacuum was approximately 0.03 . This shows a less than fourfold in the friction coefficient $(0.13)$ and more than twofold in friction endurance compared with the values obtained under ambient air. Therefore, the decrease in the friction coefficient of S-DLC films is greater under a high vacuum than under ambient air, which is supported by the micrographs of SUS440C balls (Figure 7) performed under ambient air and high vacuum. Because the friction surface in high vacuum is negligibly influenced by the effects of humidity and adsorbing gases, the friction force is strongly affected by sliding surface interactions. A carbon-sulfur bond is a high-energy bond; thus, if film transfer to ball surface was occurred, the sliding force would be low and stable because of the weak Van der Waals binding force between the transfer layer and film surface. However, the friction

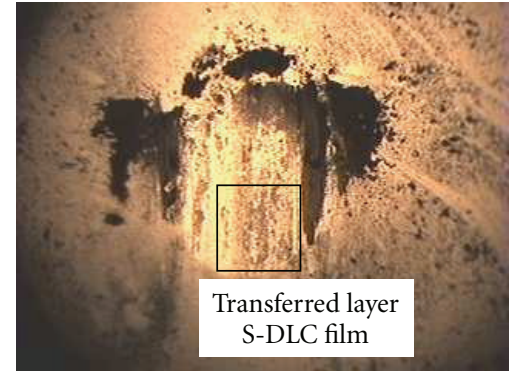

(a) $\mathrm{C} / \mathrm{S}=1: 2, \mathrm{FC}=0.05$ at 6000 cycles

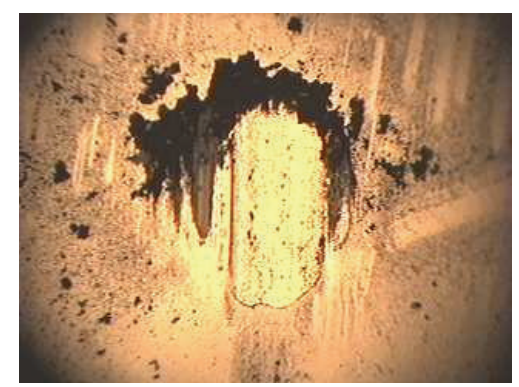

(b) $\mathrm{C} / \mathrm{S}=2: 1, \mathrm{FC}=0.13$ at 6000 cycles

FIGURE 5: Wear scar micrographs on SUS440C balls with C/S flowrate ratio of (a) $1: 2$ and (b) $2: 1$ at bias voltage of $-5 \mathrm{kV}$ under ambient air.

coefficient at a C/S flow-rate ratio of $2: 1$ does not show a significant increase in the friction endurance or decrease in the friction coefficient compared with the values obtained under ambient air.

From Figures 4 and 6, shows that the S-DLC films doped with 4.9 at.\% sulfur (C/S flow-rate ratio of $1: 2)$ at bias voltage of $0 \mathrm{kV}$ have friction coefficient of $>0.1$ and 0.03 under ambient air and high vacuum, respectively. This shows higher than friction coefficient $(<0.01)$ of carbon films doped with $5 \%$ sulfur measured under ambient air with humidity of $50 \%$ byFreyman et al. [16]. The main reasons for the higher friction coefficient were the higher internal stress, and lower hardness $>40 \%$ of the films, that is, the lower 


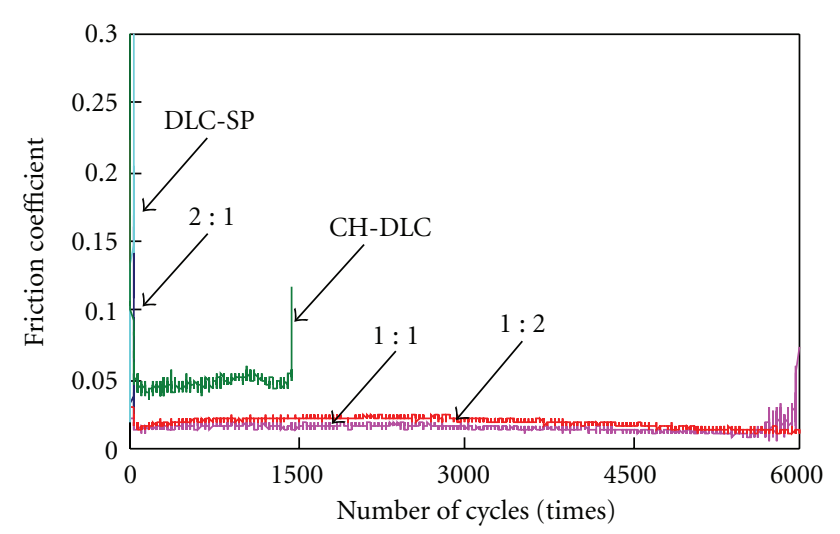

Figure 6: Changes in friction coefficients under high vacuum with bias voltage of $0 \mathrm{kV}$.

film hardness result in difficulty supporting the load, which can increase the contact area at the ball-film interface, as mentioned earlier.

The results from the DLC-SP film and the CH-DLC film are compared in Figure 6. The significant differences observed under high vacuum between the high and low friction films could be explained by the surface interactions between the carbon-covered counterfaces. High hydrogen content in a film means that hydrogen atoms are covering the surface. This leads to weak Van der Waals interactions between the sliding surfaces. For lower hydrogen content, there are not enough hydrogen atoms to shield the strong interactions between the $\pi$-orbitals of the $\mathrm{sp}^{2}$ carbon double bonds [25]. Thus, the lubricating role of hydrogen on the surface is now commonly accepted, with weak Van der Waals interactions accounting for the super low friction values $[26,27]$.

From Figure 6, in the case of the DLC-SP film, the film prepared using a graphite target leads to amorphous carbon a-C and at high $\mathrm{sp}^{3}$ content tetrahedrally coordinated amorphous carbon ta-C, with very low hydrogen content (less than 10\%) [28]. Therefore, the friction coefficient is high and failed easily during tests. In the case of the $\mathrm{CH}$ DLC film deposited from only $\mathrm{C}_{2} \mathrm{H}_{2}$ gas, the hydrogen content is very high $(30 \%-40 \%$ (a-C:H type) [29]. For the S-DLC films at C/S flow rate ratio of $1: 2$, the relative concentration values investigated by the AES test are; about $92.8 \%$ carbon, about $4.9 \%$ sulfur, and about $2.3 \%$ fluorine, such that the combined total of sulfur and fluorine is $7.2 \%$. It is speculated that the hydrogen content of the S-DLC films is less than $30 \%$, when considered and compared with the value from the CH-DLC film. The hydrogen content of the CH-DLC film deposited from $\mathrm{C}_{2} \mathrm{H}_{2}$ gas is higher than S-DLC films deposited from $\mathrm{C}_{2} \mathrm{H}_{2}$ and $\mathrm{SF}_{6}$ gas mixtures. However, the friction coefficient of the CH-DLC film shows a higher value, and the friction endurance shows number of cycle shorter than S-DLC films (although higher hydrogen content). For the main reason, that the bond strengths in diatomic molecules data given in Table 4 [19] indicate that $\mathrm{C}-\mathrm{H}$ bonds in the $\mathrm{CH}-\mathrm{DLC}$ film are broken more easily than the C-S bonds in S-DLC films.

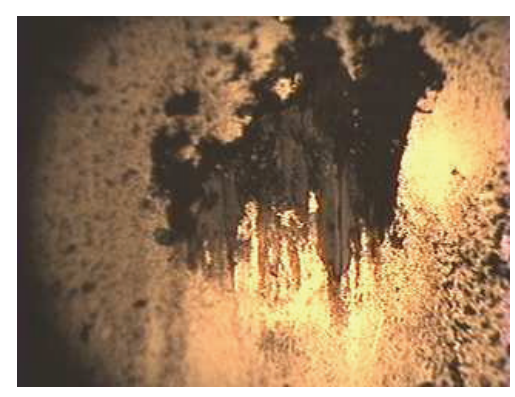

(a) $\mathrm{C} / \mathrm{S}=1: 2, \mathrm{FC}=0.13$ at 3250 cycles

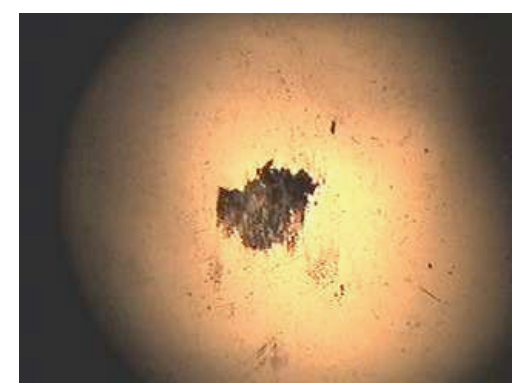

(b) $\mathrm{C} / \mathrm{S}=1: 2, \mathrm{FC}=0.03$ at 6000 cycles

FIgURE 7: Wear scar micrographs on SUS440C balls under (a) ambient air, (b) high vacuum as bias voltage of $0 \mathrm{kV}$.

TABLE 4: Bond strengths in diatomic molecules [19].

\begin{tabular}{lc}
\hline Bond type & Bond strength $(\mathrm{eV})$ \\
\hline C-H & 4.28 \\
C-F & 5.06 \\
C-S & 5.99 \\
C-C & 6.29 \\
\hline
\end{tabular}

\section{Conclusions}

Sulfur doped diamond-like carbon films (S-DLC) were prepared on $\mathrm{Si}$ (100) wafers by the PBII technique. The films were investigated in term of their structures, relative concentration, mechanical properties, and tribological properties by using Raman spectroscopy, Auger electron spectroscopy, nano-indentation hardness testing, and ball-on-disk friction testing. It was observed that by decreasing the $\mathrm{C} / \mathrm{S}$ flowrate ratio from $2: 1$ to $1: 2$, the sulfur content of the S-DLC films increases, while the hardness and the elastic modulus decrease. Additionally, when the bias voltage changes from $0 \mathrm{kV}$ to $-5 \mathrm{kV}$, the hardness and elastic modulus increase, and the specific wear rate decreases, which is due to the increased ion energy. Furthermore, a bias voltage of $-5 \mathrm{kV}$ and $\mathrm{C} / \mathrm{S}$ flow-rate ratio of $1: 2$ under ambient air shows a friction coefficient of 0.05 , which is considerable improvement in the tribological properties. This is due to the formation of transfer films on the interface. The S-DLC films show lower friction coefficients and higher friction endurance under high vacuum than the CH-DLC films, which is because $\mathrm{C}-\mathrm{H}$ bonds are broken more easily than C$\mathrm{S}$ bonds. The DLC-SP films show high friction coefficients due to very low hydrogen content. The decrease in the 
friction coefficient is greater under a high vacuum than under ambient air.

\section{Acknowledgments}

The authors would like to thank Dr. M. Iwaki, Japan Aerospace Exploration Agency, for his valuable and helpful discussions. their thanks are also extended to Mr. H. Okada, former graduate student of our Institute, who helped with the experiments. This work was partially supported by a Grant-in-Aid (no. C19560148) for Scientific Research from the Ministry of Education, Science, and Culture of Japan.

\section{References}

[1] A. H. Lettington, "Applications of diamond-like carbon thin films," Carbon, vol. 36, no. 5-6, pp. 555-560, 1998.

[2] A. Grill and V. Patel, "Tribological properties of diamond-like carbon and related materials," Diamond and Related Materials, vol. 2, no. 5, pp. 597-605, 1993.

[3] B. Bhushan, "Chemical, mechanical and tribological characterization of ultra-thin and hard amorphous carbon coatings as thin as $3.5 \mathrm{~nm}$ : recent developments," Diamond and Related Materials, vol. 8, no. 11, pp. 1985-2015, 1999.

[4] J. Noshiro, S. Watanabe, T. Sakurai, and S. Miyake, "Friction properties of co-sputtered sulfide/DLC solid lubricating films," Surface and Coatings Technology, vol. 200, no. 20-21, pp. 5849-5854, 2006.

[5] X. He, W. Li, and H. Li, "Diamond-like carbon film synthesized by ion beam assisted deposition and its tribological properties," Journal of Vacuum Science and Technology A, vol. 14, no. 4, pp. 2039-2047, 1996.

[6] J.-W. Chung, D.-H. Ko, K. Y. Eun, and K.-R. Lee, "Elastic modulus and structural evolution of diamond-like carbon films deposited by RF-PACVD," Diamond and Related Materials, vol. 11, no. 7, pp. 1441-1446, 2002.

[7] J. X. Liao, W. M. Liu, T. Xu, and Q. J. Xue, "Characteristics of carbon films prepared by plasma-based ion implantation," Carbon, vol. 42, no. 2, pp. 387-393, 2004.

[8] J. R. Conrad and T. Castagna, "Plasma source ion implantation for surface modification," Bulletin of the American Physical Society, vol. 31, p. 1479, 1986.

[9] L. Xia, M. Sun, and J. Liao, "The effect of negative bias pulse on the bonding configurations and properties of DLC films prepared by PBII with acetylene," Diamond and Related Materials, vol. 14, no. 1, pp. 42-47, 2005.

[10] J. R. Conrad, J. L. Radtke, R. A. Dodd, F. J. Worzala, and N. C. Tran, "Plasma source ion-implantation technique for surface modification of materials," Journal of Applied Physics, vol. 62, no. 11, pp. 4591-4596, 1987.

[11] A. H. Jayatissa, F. Sato, N. Saito, Y. Hirano, and K. Takizawa, "Characterization of diamond-like carbon clusters deposited by pulsed ArF laser deposition," Carbon, vol. 38, no. 8, pp. 1145-1151, 2000.

[12] J. X. Liao, W. M. Liu, T. Xu et al., "Structures and tribological properties of diamond-like carbon films prepared by plasmabased ion implantation on Si," Surface and Coatings Technology, vol. 191, no. 1, pp. 90-95, 2005.

[13] J. C. Sánchez-López, A. Erdemir, C. Donnet, and T. C. Rojas, "Friction-induced structural transformations of a diamondlike carbon coatings under various atmospheres," Surface and Coatings Technology, vol. 163-164, pp. 444-450, 2003.
[14] J. Andersson, R. A. Erck, and A. Erdemir, "Frictional behavior of diamondlike carbon films in vacuum and under varying water vapor pressure," Surface and Coatings Technology, vol. 163-164, pp. 535-540, 2003.

[15] J. Jiang, S. Zhang, and R. D. Arnell, "The effect of relative humidity on wear of a diamond-like carbon coating," Surface and Coatings Technology, vol. 167, no. 2-3, pp. 221-225, 2003.

[16] C. A. Freyman, Y. Chen, and Y.-W. Chung, "Synthesis of carbon films with ultra-low friction in dry and humid air," Surface and Coatings Technology, vol. 201, no. 1-2, pp. 164167,2006

[17] M. Tagawa, M. Ikemura, Y. Nakayama, and N. Ohmae, "Effect of water adsorption on microtribological properties of hydrogenated diamond-like carbon films," Tribology Letters, vol. 17, no. 3, pp. 575-580, 2004.

[18] S. Watanabe, J. Noshiro, and S. Miyake, "Friction properties of WS2/MoS2 multilayer films under vacuum environment," Surface and Coatings Technology, vol. 188-189, no. 1-3, pp. 644-648, 2004.

[19] R. C. Weast, Ed., CRC Handbook of Chemistry and Physics, CRC Press, Boca Raton, Fla, USA, 61st edition, 1981.

[20] L. G. Jacobsohn and F. L. Freire Jr., "Influence of the plasma pressure on the microstructure and on the optical and mechanical properties of amorphous carbon films deposited by direct current magnetron sputtering," Journal of Vacuum Science and Technology A, vol. 17, no. 5, pp. 2841-2849, 1999.

[21] J. Qi, J. B. Luo, S. Z. Wen, J. Wan, and W. Z. Li, "Mechanical and tribological properties of non-hydrogenated DLC films synthesized by IBAD," Surface and Coatings Technology, vol. 128-129, pp. 324-328, 2000.

[22] M. A. Capano, N. T. McDevitt, R. K. Singh, and F. Qian, "Characterization of amorphous carbon thin films," Journal of Vacuum Science and Technology A, vol. 14, no. 2, pp. 431-435, 1996.

[23] F. L. Freire Jr., G. Mariotto, R. S. Brusa, A. Zecca, and C. A. Achete, "Structural characterization of amorphous hydrogenated carbon and carbon nitride films deposited by plasma-enhanced CVD," Diamond and Related Materials, vol. 4, no. 4, pp. 499-502, 1995.

[24] D. Chicot and J. Lesage, "Absolute hardness of films and coatings," Thin Solid Films, vol. 254, no. 1-2, pp. 123-130, 1995.

[25] C. Donnet, A. Grill, J. Fontaine et al., in Lubrication at Frontier, D. Dowson et al., Ed., vol. 36 of Tribology Series, pp. 333-341, Elsevier, Amsterdam, The Netherlands, 1999.

[26] A. Erdemir, O. L. Eryilmaz, and G. Fenske, "Synthesis of diamondlike carbon films with superlow friction and wear properties," Journal of Vacuum Science and Technology A, vol. 18, no. 4, pp. 1987-1992, 2000.

[27] A. Erdemir, "The role of hydrogen in tribological properties of diamond-like carbon films," Surface and Coatings Technology, vol. 146-147, pp. 292-297, 2001.

[28] J. Fontaine, T. Le Mogne, J. L. Loubet, and M. Belin, "Achieving superlow friction with hydrogenated amorphous carbon: some key requirements," Thin Solid Films, vol. 482, no. 1-2, pp. 99-108, 2005.

[29] P. Koidl, C. Wagner, B. Dischler, J. Wagner, and M. Ramsteiner, Materials Science Forum, vol. 52, p. 41, 1990. 

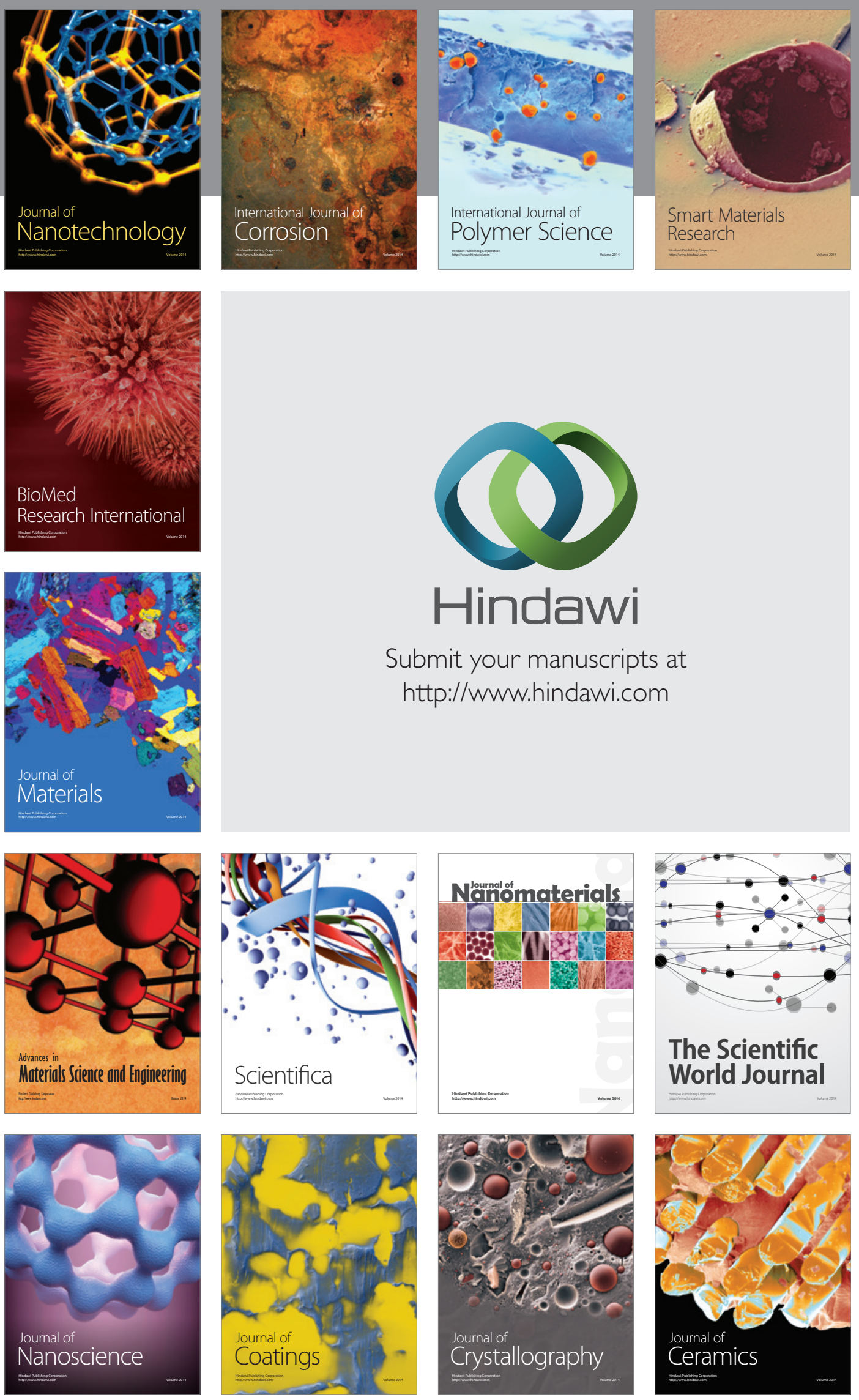

The Scientific World Journal

Submit your manuscripts at

http://www.hindawi.com

\section{World Journal}

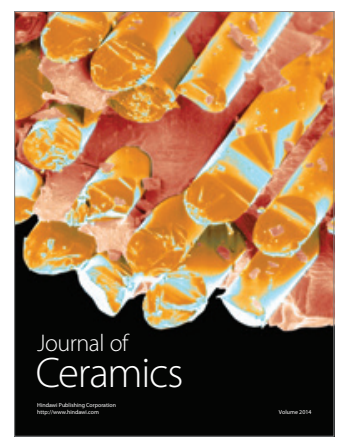

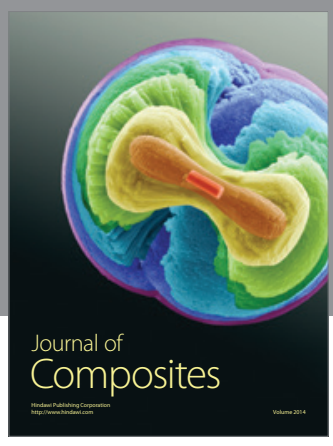
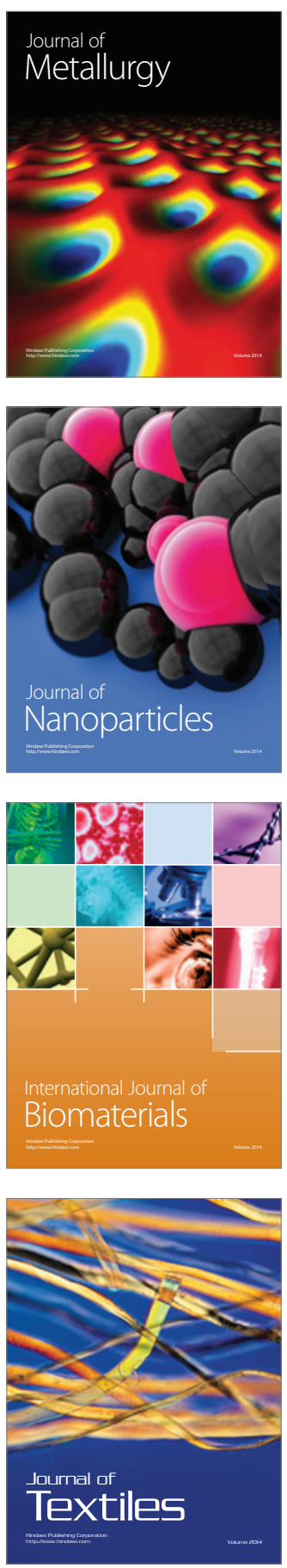